\title{
Intrahepatic migration of pancreatic stent after pancreaticoduodenectomy: percutaneous cholangioscopic retrieval is feasible
}

\author{
Su Kah Goh 지 , ${ }^{1,2}$ Hong Kuan Kok, ${ }^{3,4}$ Nezor Houli ${ }^{1}$
}

${ }^{1}$ Hepatopancreaticobiliary Unit, Northern Hospital Epping, Epping, Victoria, Australia ${ }^{2}$ Hepatopancreaticobiliary and Transplant Unit, Austin Health, Heidelberg, Victoria, Australia ${ }^{3}$ Interventional Radiology Service, Northern Hospital Epping, Epping, Victoria, Australia

${ }^{4}$ School of Medicine, Faculty of Health, Deakin University, Waurn Ponds, Victoria, Australia

Correspondence to Su Kah Goh;

sukah.goh@austin.org.au

Accepted 13 September 2021

Check for updates

(c) BMJ Publishing Group Limited 2021. No commercial re-use. See rights and permissions. Published by BMJ.

To cite: Goh SK, Kok HK, Houli N. BMJ Case Rep

2021:14:e244380

doi:10.1136/bcr-2021-

244380

\section{DESCRIPTION}

Transanastomotic stents are often used in pancreaticoduodenectomy to maintain ductal patency and support the healing of anastomoses. This is widely performed, with a view of minimising postoperative pancreatic fistulas. ${ }^{12}$ The use of transanastomotic stents is associated with sepsis, bleeding, pancreatitis and migration. Rarely, such stents have been reported to migrate into the biliary tree. ${ }^{34}$ Retention may lead to inflammation and cholangitis. ${ }^{56}$

Herein, we describe a case where a pancreatic stent had migrated into a segment VI intrahepatic duct following a pancreaticoduodenectomy.

A patient underwent a pancreaticoduodenectomy for a pancreatic neoplasm. Gastrointestinal continuity was accordingly restored. The pancreaticojejunostomy was reconstructed in an end-to-side and duct-to-mucosa fashion. A transanastomotic pancreatic stent (Cook Medical) was placed. This was followed by an end-to-side hepaticojejunostomy, loop gastrojejunostomy and a Braun enteroenterostomy.

Twelve months later, the patient developed episodic cholangitis. Cross-sectional imaging demonstrated a migrated pancreatic stent in a segment VI duct. Two attempts at percutaneous transhepatic retrieval were unsuccessful, owing to sharp acute angulation of the segment VI duct origin and distal stent impaction.

Subsequently, an interventional radiology (IR)-assisted percutaneous cholangioscopic stent retrieval was performed. An existing 8-French internal-external biliary drain (Cook Medical) was upsized and a safety guidewire was positioned across the hepaticojejunostomy to secure the access.

The segment VI duct was cannulated using a reverse curve catheter under fluoroscopic guidance to facilitate placement of a guidewire. Initial attempts at trawling the duct was unsuccessful. A CHF-V choledochoscope (Olympus) with a $2.8 \mathrm{~mm}$ working channel was subsequently advanced over the wire into the segment VI duct. The guidewire facilitated the passage of the choledochoscope across an acute angle between the established tract and the opening of the segment VI duct. The stent was visualised and the tip of the stent was secured using a ZeroTip Nitinol Retrieval Basket (Boston Scientific). Under direct cholangioscopic vision and fluoroscopic control (figure 1), the stent was removed.
The management of perioperative complications after pancreatic surgery is challenging. The need for retrieving retained stents is dependent on the patient's clinical status. Ongoing sepsis prompted the need for stent retrieval in this case.

Techniques such as IR-assisted percutaneous snaring, endoscopic retrograde cholangiopancreatography (ERCP), ERCP with SpyGlass (Boston Scientific) or balloon-assisted enteroscopy have been described for retrieving retained biliary foreign bodies, however, these techniques can be challenging. $^{7-9}$

IR-assisted percutaneous cholangioscopy using choledochoscopes to manage biliary stones is well described. ${ }^{1011}$ This technique is also used at our institution to manage complex intrahepatic biliary stones. Adopting a similar approach, we used this technique to remove a migrated pancreatic stent. Recently, the use of IR-assisted percutaneous cholangioscopy with Spyglass have also been described for successful treatment of biliary stones, removal of foreign body and biopsy of suspicious strictures. ${ }^{1213}$

As highlighted by this case, the use of an IR-assisted percutaneous cholangioscopic approach to salvage the retrieval of retained intrahepatic foreign bodies is feasible, particularly when faced with challenging or unfavourable ductal anatomy. Broadening the armamentarium of such minimally

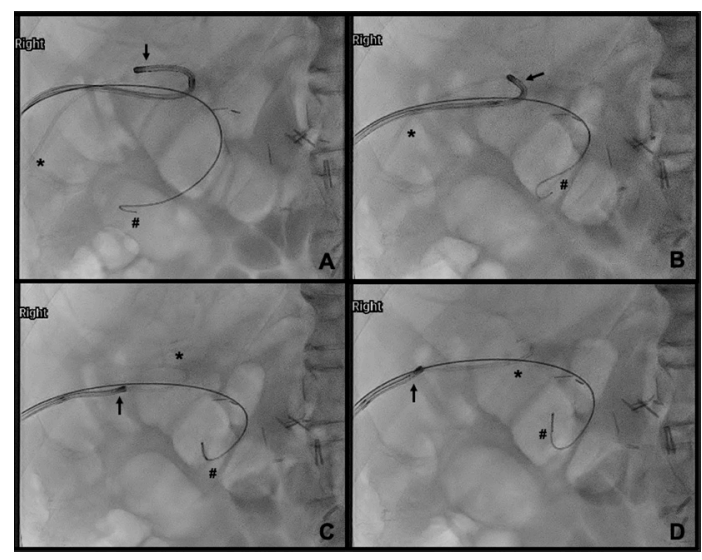

Figure 1 Interval images showing the successful retrieval of a pancreatic stent that migrated into a segment VI intrahepatic duct using an interventional radiology assisted percutaneous cholangioscopic approach. *Tip of faintly radio-opaque stent, \#safety wire traversing the hepaticojejunostomy with the tip situated in the jejunum, arrow: tip of the choledochoscope. 
invasive rescue therapies is useful and may reduce the need of invasive open procedures.

\section{Learning points}

- Migration of transanastomotic stents after pancreaticoduodenectomy is an uncommon but recognised postoperative complication.

- The management of stents that have migrated into the intrahepatic biliary system can be challenging.

- Interventional radiology assisted percutaneous cholangioscopy is a feasible approach for the retrieval of intrahepatic foreign bodies.

Contributors SKG contributed to the conception and interpretation of the data. HKK and NH contributed to the conception of the manuscript and acquisition of the clinical data. SKG, HKK and NH contributed to the writing and the revision of the manuscript equally. All authors approved this version of the manuscript for publication and ave agreed to be accountable for all aspects of the work.

Funding The authors have not declared a specific grant for this research from any funding agency in the public, commercial or not-for-profit sectors.

Competing interests None declared.

Patient consent for publication Not required.

Provenance and peer review Not commissioned; externally peer reviewed.

ORCID iD

Su Kah Goh http://orcid.org/0000-0002-6684-2521

\section{REFERENCES}

1 Lai ECH, Lau SHY, Lau WY. Measures to prevent pancreatic fistula after pancreatoduodenectomy: a comprehensive review. Arch Surg 2009;144:1074-80.
2 G-q Z, Li X-H YX-J, Chen H-B. Internal versus external drainage with a pancreatic duct stent for pancreaticojejunostomy during pancreaticoduodenectomy for patients at high risk for pancreatic fistula: a comparative study. Journal of Surgical Research 2018;232:247-56.

3 Helaly M, Sriwi D, Alkholaidi WS, et al. Retrograde pancreatic duct stent migration into the biliary tract presenting as a rare early complication of pancreaticoduodenectomy (Whipple procedure). Am J Case Rep 2019:20:1864-8.

4 Bawany MZ, Rafiq E, Thotakura R, et al. Successful management of recurrent biliary colic caused by pancreatic stent migration after Whipple procedure. J Interv Gastroenterol 2012;2:205-6.

5 Yang E, Eskandari A, Chang MA, et al. Cholangitis caused by a migrated pancreatic duct stent into the bile duct after pancreaticoduodenectomy. ACG Case Rep J 2020;7:e00477.

6 Rezvani M, O'Moore PV, Pezzi CM. Late pancreaticojejunostomy stent migration and hepatic abscess after Whipple procedure. J Surg Educ 2007;64:220-3.

7 Layec S, D'Halluin P-N, Pagenault M, et al. Removal of transanastomotic pancreatic stent tubes after pancreaticoduodenectomy: a new role for double-balloon enteroscopy. Gastrointest Endosc 2010;72:449-51.

8 Rastegari S, Craig C, John E, et al. Use of intraductal cholangioscopy devices to retrieve migrated pancreatic stents. Endoscopy 2020;52:E202-3.

9 Crowley JJ, Zajko AB, Fitz CR, et al. Retained surgical stents as a cause of biliary obstruction in pediatric liver transplants. Pediatr Radiol 2015:45:430-4.

10 Cannavale A, Bezzi M, Cereatti F, et al. Combined radiological-endoscopic management of difficult bile duct stones: 18-year single center experience. Therap Adv Gastroenterol 2015;8:340-51.

11 Ahmed 0, Mathevosian S, Arslan B. Biliary interventions: tools and techniques of the trade, access, cholangiography, biopsy, Cholangioscopy, Cholangioplasty, stenting, stone extraction, and brachytherapy. Semin Intervent Radiol 2016;33:283-90.

12 Gerges C, Vázquez AG, Tringali A, et al. Percutaneous transhepatic cholangioscopy using a single-operator cholangioscope (pSOC), a retrospective, observational, multicenter study. Surg Endosc 2021;47.

13 Kim W, Cheon Y, JH M. Percutanous cholangioscopic removal of a retained surgical needle 20 years after open cholecystectomy. The Korean Journal Of Pancreas And Biliary Tract 2011;16:36-9.

Copyright 2021 BMJ Publishing Group. All rights reserved. For permission to reuse any of this content visit

https://www.bmj.com/company/products-services/rights-and-licensing/permissions/

BMJ Case Report Fellows may re-use this article for personal use and teaching without any further permission.

Become a Fellow of BMJ Case Reports today and you can:

- Submit as many cases as you like

- Enjoy fast sympathetic peer review and rapid publication of accepted articles

- Access all the published articles

- Re-use any of the published material for personal use and teaching without further permission

Customer Service

If you have any further queries about your subscription, please contact our customer services team on +44 (0) 2071111105 or via email at support@bmj.com.

Visit casereports.bmj.com for more articles like this and to become a Fellow 